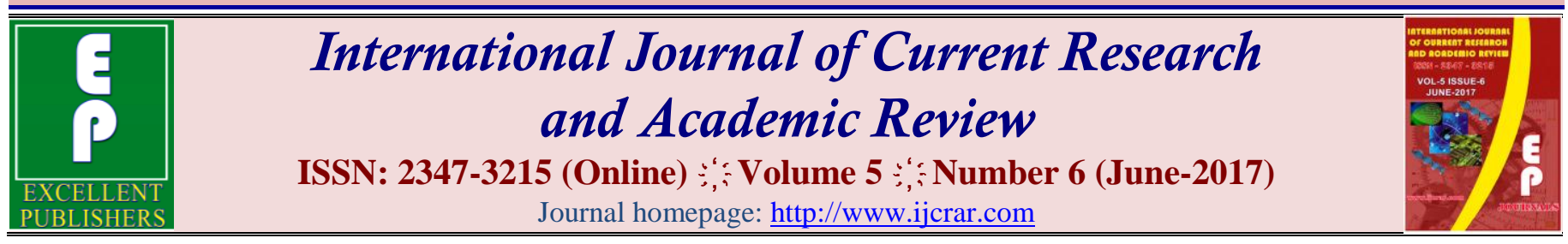

doi: https://doi.org/10.20546/ijcrar.2017.506.010

\title{
Impact of the Anabolic Androgenic Steroid "Nandrolone Decanote" on the Histological and Ultrastructural Characteristics of Adrenal Cortex of Adult Male Rat
}

\author{
Hanaa R. Aboelwafa* \\ Department of Biological and Geological Sciences, Faculty of Education, Ain Shams University, Roxy, Cairo, Egypt \\ *Corresponding author
}

\begin{abstract}
The anabolic androgenic steroid nandrolone decanote (ND) is a synthetic testosterone derivative represented the most widely abused drugs all over the world with the purpose of ameliorating athletic efficiency and appearance. Despite the prevailing misuse of ND, the endocrine influences of supraphysiologic dosages of this compound still ambiguous. The present investigation was designed to study the effect of therapeutic and supraphysiologic doses of ND on histological and ultrastructural features of rats adrenal cortices. Twenty-four animals were grouped into control, ND therapeutic dose, and ND supraphysiologic dose groups. The current results showed that the adrenal cortices of rats treated with ND therapeutic dose exhibited mild alteration of their adrenocortical zones; ZG, ZF and ZR. Whereas, the adrenal cortices of rats treated with the ND supraphysiological dose manifested severe degenerative changes represented as reduction in the thickness of all adrenocortical zones, compression of their cells which appeared with vacuolated cytoplasm and their nuclei showed signs of pyknosis, karyorrhexis and karyolysis. Most of the adverse impacts following the abuse of ND resulted from the enhancement of normal physiologic response to testosterone by either direct receptor agonist activity or suppression of steroid biosynthesis. The current histological and ultrastructural studies emphasis that the supraphysiologic dose of ND induced serious hazardous alterations in the adrenal cortex which might be reflected in suppression of steroid hormones biosynthesis. Therefore, these results are exceedingly pertinent to highlight the prospective hazard of the indistinctive utilization of the AASs in sports by athletes and bodybuilders, as well as by adolescents.
\end{abstract}

\section{Article Info}

Accepted: 05 June 2017

Available Online: 20 June 2017

\section{Keywords}

Anabolic androgenic steroid,

Nandrolone decanote,

Adrenal cortex,

Histology,

Utrastructure.

\section{Introduction}

Anabolic-androgenic steroids (AASs) are synthetic derivates of testosterone widely utilized as androgen replacement therapy and as chemotherapy for the treatment of different types of cancer (Kamel et al., 2001). On the other hand, there is a broad nonmedical use of these steroids by athletes and adolescents that has triggered considerable apprehensive (Kindlundh et al., 2001; Hartgens and Kuipers, 2004; Talih et al., 2007; Kanayama et al., 2010). During the last decades, AASs have been utilized at doses 10-100 times the recommended therapeutic dose by many athletes and bodybuilders to reinforce their physical performance, increase muscle mass and condense training regimens (Gruber and Pope, 2000; Kuhn, 2002). 
Nandrolone decanoate (ND) is the most widely artificial anabolic derivatives of androgen utilized for the treatment of benign prostate hyperplasia and cancer prostate as a testosterone-replacement therapy. Also, it has increased notably utilization in the therapy of definite diseases as muscle wasting, osteoporosis, growth disorders and control of refractory anemia (Chawla et al., 2009; Saha et al., 2009; Allouh and Rosser, 2010). ND simulates testosterone in its structure yet, it is supposed as a weak androgenic steroid owing to its transformation to dihydronandrolone (DHN) (Mottram and George, 2000; Lee et al., 2010; Purkayastha and Mahanta, 2012).

The utilization of AASs, including ND was found to be the cause of several adverse physical and mental influences, including increased risk of cardiovascular and hepatic disease, aggressiveness, gloominess, impaired cognitive functions and gynecomastia (Kurling et al., 2005; Kicman, 2008; Magnusson et al., 2009; Hallberg, 2011). Alterations in mood, delusions and euphoria, as well as drastic behavior are correlating with the prolonged utilization of AASs (Gruber and Pope, 2000; Perry et al., 2003; Matrisciano et al., 2010).

Although several studies on the impacts of AAS derivatives on various body organs, the endocrine influences of supraphysiologic dosage of these agents still unclear. Thus, the present investigation was designed to study the impact of therapeutic and supraphysiological doses of ND on the histological and ultrastructural characteristics of adrenal cortex of adult male rat using light and transmission electron microscopy (TEM) techniques.

\section{Materials and Methods}

\section{Investigated animals}

Twenty-four adult male albino rats (Rattus norvegicus) at an age of 16 weeks and a weight of $180 \mathrm{~g}$ were equally allocated into three groups. They were purchased from the animal house of Theodor Bilharz Research Institute (TBRI), El-Giza, Egypt.

The rats were kept two per cage in air-conditioned room $\left(25 \pm 2^{\circ} \mathrm{C}\right.$ temperature, $55 \pm 5 \%$ relative humidity, and a 12-h light/dark cycle) and provided with adequate amount of food and water. The animals were left for a week prior to the beginning of the experiment for accommodation. All animal experiments were confirmed by the local Institutional Animal Ethics Committee of Ain Shams University.

\section{Investigated drug}

The experimental drug is nandrolone decanoate (ND; Deca-Durabolin $^{\circledR}$ ). It is available in the form of vials; each of them contains $25 \mathrm{mg} / \mathrm{ml}$ oily solution. ND is manufactured by Nile Co. for Pharmaceutical and Chemical Industries, Cairo, Egypt.

\section{Experimental Design}

All animals were subjected to daily intramuscular (i.m.) injections in the hind limb, once a day for 14 days, as follows:

Group I: the ND therapeutic dose-treated rats $(\mathrm{n}=6)$ were received $0.4 \mathrm{mg} / \mathrm{kg} \mathrm{ND}$. This dose is chosen to ascertain the prescribed therapeutic dose of ND in humans (Tamaki et al., 2003).

Group II: the ND supraphysiologic dose-treated rats $(\mathrm{n}=$ 6) were administered $15 \mathrm{mg} / \mathrm{kg}$ ND. This dose is approximately 40-times higher than the therapeutic dose recommended for humans and corresponds to the heavy dose generally used by the anabolic steroid abusers (Fudala et al., 2003; Lindblom et al., 2003; Silvia et al., 2012; Rainer et al., 2014).

Group III: the control rats $(n=6)$ were given an equal volume of the oil vehicle (peanut oil) alone. When the experimental time period was finished, control and treated rats were fasted overnight and then anesthetized under light ether anesthesia. Adrenal glands of all rats were dissected out and were immediately fixed in different fixatives for histological and ultrastructural examinations.

\section{Histological preparations}

The right adrenal glands from the control and experimental rats were rapidly fixed for $24 \mathrm{~h}$ in aqueous Bouin's fixative. After that, they were processed for the paraffin sectioning preparation as described previously by Bancroft and Gamble (2002). After routine processing, the haematoxylin-eosin (H\&E) stained sections were examined and photographed with a light microscope.

\section{Ultrastructural preparations}

The left adrenal glands of rats from all experimental groups were cut into small fragments, fixed in cold mixture of formalin and glutaraldehyde (4:1) for $24 \mathrm{~h}$, 
and then they were post fixed in $1 \%$ osmium tetroxide in $0.1 \mathrm{M}$ phosphate buffer. Following fixation, they were processed for the normal procedures of TEM evaluation as explained by Dykstra et al., (2002). After routine processing, toluidine blue semithin stained sections were examined with a light microscope to select the adrenocortical zones, and then ultrathin sections were cut, mounted on grids, stained by uranyl acetate and lead citrate, then examined and photographed by JEOL.JEM1400-EX-ELECTRON MICROSCOPE at the Electron Microscopy Department of TBRI, El-Giza, Egypt.

\section{Results and Discussion}

\section{Histological results}

\section{Control group}

The adrenal cortex of control rat revealed normal characteristic organization. It is enclosed within a fibrous connective tissue capsule which is formed of fibrous elements, and composed of three distinguished zones; zona glomerulosa $(\mathrm{ZG})$, fasciculate $(\mathrm{ZF})$ and reticularis (ZR), respectively (Figs. 1A-1D). ZG formed of pyramidal or columnar cells which are arranged in glomeruli-like structures separated by thin trabeculae that being extended from the outer capsule. ZG cells appeared with large rounded to oval basophilic nuclei and acidophilic cytoplasm (Fig. 1B). ZF composed of columnar or rather polyhedral cells which are coordinated in fasciculae formed of one or two cell thick, and separated by narrowed blood capillaries lined with endothelial cells. The cells of ZF appeared with granulated eosinophilic cytoplasm enclosing spherical basophilic nuclei (Figs. 1B and 1C). ZR characterized by its irregular network of intermingled cords which are detached by wide blood sinusoids that lined with endothelial cells. ZR cells are short columnar in shape with rounded basophilic nuclei and moderately eosinophilic cytoplasm (Fig. 1D).

\section{The ND therapeutic dose group}

Examination of H\&E stained sections of the adrenal glands of rats treated with therapeutic dose of ND showed mild alteration of the adrenocortical zones; ZG, $\mathrm{ZF}$ and $\mathrm{ZR}$ as noticed the in figures $2 \mathrm{~A}-2 \mathrm{D}$. The cells of the three regions appeared with a relative normal arrangement in comparison with the control specimens (Fig. 2A). ZG cells arranged in a relative glomeruli-like structure, which appeared relatively compressed and separated by the delicate trabeculae. Some ZG cells possessed vacuolated cytoplasm with their nuclei showed symptoms of pyknosis (Fig. 2B). Also, ZF cells arranged in cords almost similar to the normal arrangement of the control ones, and possessed granulated eosinophilic cytoplasm and rounded nuclei in the most of them. But, some cells manifested obvious vacuolated cytoplasm with pyknotic, karyorrhectic and karyolysed nuclei. Blood capillaries in between ZF cells were observed engorged with stagnant blood masses (Figs. 2B and 2C). Similarly, ZR cells showed relative normal organization with dilated blood sinusoids that are lined with endothelial cells were seen (Fig. 2D). The majority of ZR cells appeared with normal eosinophilic cytoplasm and rounded nuclei, whereas some cells displayed pyknotic and karyolysed nuclei, as well as vacuolated cytoplasm as illustrated in figure 2D.

\section{The ND supraphysiological dose group}

Light microscopic examination of the adrenal glands of rats treated with the ND supraphysiological dose illustrated severe degenerative changes represented as reduction in the thickness of the three adrenocortical zones which were resulted from the compression of their cells as clearly observed in figures 3A-3D. Most ZG cells appeared compressed, lost their familiar glomerular organization, and displayed clear symptoms of necrosis revealed as vacuolated cytoplasm and pyknotic nuclei (Figs. 3B and 3C). Also, ZF cells appeared disarranged, lost their familiar fasciculae appearance revealing obvious fibrotic areas among their destructed cells. Their nuclei manifested clear signs of pyknosis, karyorrhexis and karyolysis, while their cytoplasm showed abundant vacuoles of variable sizes (Figs. 3B and 3D). The blood capillaries in between ZF cells were hardly distinguished (Fig. 3C). Similarly, ZR cells lost their normal architecture, appeared compressed with vacuolated cytoplasm and deteriorated nuclei revealed clear signs of pyknosis (Fig. 3D). The blood sinusoids separating ZR cells appeared enlarged and engorged with stagnant blood masses in their lumina as clearly seen in figure 3D.

Figure 1 shows the light micrographs of $H \& E$ stained sections of adrenal gland of control rat showing (A) normal architecture of the adrenal cortex consisting of three consecutive zones; zona glomerulosa (ZG), fasciculata (ZF) and reticularis (ZR), and surrounding by a capsule (Ca). (B) Glomerular organization of ZG cells (ZGC) separated by fine trabeculae $(\mathrm{Tb})$ that extended from the capsule (Ca). (C) ZF cells (ZFC) normally arranged in fasciculae separated by narrow blood capillaries (Cap) that are lined with endothelial cells 
(EC). (D) ZR cells (ZRC) arranged in an ordinary irregular network of intermingled cords that are separated by wide blood sinusoids (BS) lined with endothelial cells (EC).

Figure 2 shows light micrographs of $H \& E$ stained sections of adrenal gland of ND therapeutic dose-treated rat showing (A) a relative normal arrangement of the adrenocortical zones; ZG, ZF and ZR, being enclosed by the capsule (Ca). (B) Magnified part of ZG and ZF cells displaying their familiar arrangement. Despite of this arrangement, some of their cells exhibiting vacuolated cytoplasm (V) and pyknotic nuclei (Pk). The capsule (Ca) appears relatively normal. (C) ZF cells exhibiting a relative normal arrangement having granulated eosinophilic cytoplasm and rounded nuclei. Some cells showing obvious vacuolated cytoplasm (V) and pyknotic $(\mathrm{Pk})$ and karyolysed $(\mathrm{Kl})$ nuclei. Blood capillaries (Cap) engorged with blood cells (asterisks) are also noticed. (D) ZR cells displaying relatively normal characters in the presence of normal eosinophilic cytoplasm and rounded nuclei in the most of these cells. Some reticularis cells reveal pyknotic (Pk) and karyolysed (Kl) nuclei. Wide blood sinusoids (BS) lined with intact endothelial cells are also observed.

Figure 3 shows light micrographs of $H \& E$ stained sections of adrenal gland of ND supraphysiological dose treated rat showing (A) shrinkage of the adrenocortical zones; ZG, ZF and ZR. Irregular capsule $(\mathrm{Ca})$ is also seen. (B) Glomerulosa (ZGC) and fasciculate (ZFC) cells are compressed, lost their familiar organization and designating clear fibrotic areas (F). Vacuolated (V) cytoplasm and necrotic nuclei showing symptoms of pyknosis (Pk), karyorrhexis (Kh) and karyolysis (Kl) are observed in both ZG and ZF cells. (C) ZF cells (ZFC) exhibit cytoplasmic vacuolation $(\mathrm{V})$ with variable sizes and their nuclei show signs of pyknosis (Pk), karyorrhexis (Kh) and karyolysis (Kl). (D) ZR cells (ZRC) lose their normal arrangement with the blood sinusoids (BS) separating them being enlarged and loaded with stagnant blood (asterisks) in their lumina.

\section{Ultrastructural results}

\section{Control adrenal cortex}

TEM examination of the adrenal cortices of control rats illustrated normal fine structural characteristics of the cells of all adrenocortical regions; $\mathrm{ZG}, \mathrm{ZF}$ and $\mathrm{ZR}$ as clearly seen in micrographs (4A-4C). ZG cells appeared with different mitochondrial configuration varying from oval to spherical shapes with a specific tubule-saccular cristae, a fair amount of smooth endoplasmic reticulum and lipid droplets. The nuclei of these cells are rounded or oval in shape; sometimes wavy in appearance ensheathed by double nuclear envelopes and having nucleoli, homogenous euchromatin and peripheral dense heterochromatin (Fig. 4A). ZF cells exhibit the regular fine characteristic features including; abundance of rounded mitochondria with obvious tubular cristae, smooth endoplasmic reticulum in the form of branching tubules, fair amount of lysosomes and richness of lipid droplets as obviously noticed in micrograph (4B). The same figure demonstrates their nuclei which are large, rounded in shape, enclosed within the nuclear envelopes and possessed prominent nucleoli, dense peripheral heterochromatin and lightly stained euchromatin. ZR cells are distinguished by their richness of rounded mitochondria with intensive tubular cristae, smooth endoplasmic reticulum, lysosomes and abundant lipid droplets of different sizes. Their nuclei are spherical or oval in shape containing condensed heterochromatin, euchromatin and prominent nucleoli (Fig. 4C).

\section{The ND therapeutic dose group}

Mild fine structural changes were recorded in the adrenal cortices of ND therapeutic dose-treated rats as displayed in micrographs (5A-5C). ZG cells contained mitochondria with electron-dense matrices, lipid droplets of variable sizes, and electron-dense nuclei (Fig. 5A). ZF cells showed mitochondria filled with tightly packed tubular cristae, other mitochondria appeared destructed with more electron-dense matrices, besides the accumulation of various sized lipid droplets. Some nuclei displayed signs of pyknosis and karyorrhexis (Fig. 5B). Similarly, ZR cells possessed deformed mitochondria with electron-dense matrices and tightly packed tubular cristae, in addition to accumulated lipid droplets of different sizes, and pyknotic nuclei which were surrounded by irregular ruptured nuclear envelopes and contained electron-dense heterochromatin and euchromatin materials (Fig. 5C).

\section{The ND supraphysiological dose group}

TEM examination of the adrenal cortices of the ND supraphysiological dose-treated rats displayed severe ultrastructural changes of the cells of the adrenocortical zones; ZG, ZF and ZR as observed in the micrographs $(6 \mathrm{~A}-6 \mathrm{C})$. Distorted ZG cells revealed deteriorated mitochondria with loss of their cristae configuration; other mitochondria appeared with degenerated cristae 
and cavitations. Increased lipid droplets and devoid of smooth endoplasmic reticulum were also noticed. Their nuclei became shrunken, irregular in shape, surrounded by broken nuclear envelopes and contained peripheral heterochromatin and euchromatin, revealing signs of pyknosis as manifested in micrograph (6A). Also, ZF cells exhibited obvious fine structural alterations that were detected in both the cytoplasm and the nuclei (Fig. 6B). They are characterized by the appearance of fingerprint-like configuration composed of concentric whorls of membranes, mitochondria with electrondensities, extensive aggregation of lipid droplets throughout the cytoplasm, and absence of smooth endoplasmic reticulum. Their nuclei appeared shrunken, showed clear signs of pyknosis and karyorrhexis and they were surrounded by broken nuclear envelopes and contained an obvious electron-dense nucleoli, marginated heterochromatin and euchromatin (Fig. 6B). Several conspicuous lesions were encountered in ZR cells included the abnormally fingerprint-like configuration, deformed mitochondria with some of them showing ruptured mitochondrial membrane, degenerated cristae and cavitation, lipid droplets, and cytoplasmic vacuoles, besides nuclear pyknosis (Fig. 6C).

Figure 4 shows electron micrographs of adrenal cortex of control rat showing (A) ZG cell possesses mitochondria (M) with tubulo-saccular cristae, smooth endoplasmic reticulum (SER) lipid droplets (LD), lysosomes (Ly) and a nucleus $(\mathrm{N})$ which is surrounded by nuclear envelope $(\mathrm{NE})$ and has a nucleolus $(\mathrm{Nu})$, marginated heterochromatin (Hc) and euchromatin (Ec). (B) ZF cell loaded with numerous mitochondria $(\mathrm{M})$ having tubular cristae, smooth endoplasmic reticulum (SER), free ribosomes (R), lysosomes (Ly), and abundant lipid droplets (LD). Part of its distinct rounded nucleus (N) containing a nucleolus $(\mathrm{Nu})$, peripheral heterochromatin (Hc) and flocculent euchromatin (Ec) is clearly observed. (C) ZR cell illustrating prominent rounded mitochondria (M) with tubular cristae, smooth endoplasmic reticulum (SER), lysosomes (Ly), lipid droplets (LD), and rounded nucleus $(\mathrm{N})$ possessing distinct nucleolus $(\mathrm{Nu})$, peripheral heterochromatin $(\mathrm{Hc})$ and euchromatin $(\mathrm{Ec})$.

Figure 5 shows electron micrographs of adrenal cortex of ND therapeutic dose-treated rats showing (A) ZG cell possesses electron-dense mitochondria $(\mathrm{M})$, increased sized lipid droplets (LD), and a nucleus (N). (B) ZF cell showing karyorrhectic nucleus $(\mathrm{N})$ surrounded with ruptured nuclear envelope (NE) and contained fragmented heterochromatin ( $\mathrm{Hc}$ ) and euchromatin $(\mathrm{Ec})$ materials. In addition, slightly changes in configuration of mitochondria; some of them appeared electron-dense (M) and the others filled with tightly packed tubular cristae (asterisks). Large lipid droplets (LD) are seen in the ground cytoplasm. (C) ZR cell displaying cytoplasm loaded with destructed mitochondria (M), lipid droplets (LD) and destructed smooth endoplasmic reticulum (SER). The nucleus (N) shows clear signs of pyknosis; it is surrounded by fragmented irregular nuclear envelope (NE) and contains extensive electron dense heterochromatin $(\mathrm{Hc})$ and euchromatin $(\mathrm{Ec})$.

Electron micrographs of adrenal cortex of ND supraphysiological dose treated rats showing (A) deteriorated ZG cell with an obvious wrinkled nucleus (N) surrounded by ruptured nuclear envelope (NE) and contained electron-dense heterochromatin $(\mathrm{Hc})$ and euchromatin ( $\mathrm{Ec})$ materials (Fig. 6). Electron-dense mitochondria (M) with different configuration and degenerated cristae, other mitochondria with cavitation (asterisks), lipid droplets (LD) and vacuoles (V) are seen in the cytoplasm. (B) Destructed ZF cell showing distinct fingerprint-like configuration (FP) consists of concentric whorls of membranes, deteriorated mitochondria (M) with tightly packed cristae, vacuoles (V), and deformed nucleus $(\mathrm{N})$ ensheathed with a ruptured nuclear envelope (NE) and possesses electron-dense nucleolus ( $\mathrm{Nu}$ ), heterochromatin (Hc) and euchromatin (Ec). (C) Deteriorated ZR cell reveals also the distinct fingerprintlike configuration (FP), mitochondria (M) having vacuolar degeneration (asterisk), vacuoles (V), and pyknotic nucleus (N) possessing electron-dense nucleolus $(\mathrm{Nu})$, heterochromatin $(\mathrm{Hc})$ and euchromatin (Ec).

The adrenal gland is the most significant and fundamental endocrine organ in the body taking charge of the synthesis and secretion of considerable steroid hormones which perform serious and substantial functions (Fawcett and Jensh, 2002). The mammalian adrenal gland distinguishes two distinct anatomical zones; an outer cortex covering an inner medulla differing in embryological origin and function (Sicard $e t$ al., 2007). The cortex exemplifies $80-90 \%$ of the adrenal and is composed of cords of epithelial cells that are directly related to the blood vessels. These epithelial cells are grouped into three different adrenocortical zones arranged as zona glomerulosa (ZG), zona fasciculate $(\mathrm{ZF})$, and zona reticularis (ZR). The cells of $\mathrm{ZG}$ secrete significant amounts of the mineralcorticoids aldosterone, and ZF cells secrete the glucocorticoids cortisol and corticosterone, in addition to small amounts of adrenal androgens and estrogens, while ZR cells 
secrete the adrenal androgens androstenedione, dehydroepiandrosterone (DHEA) and small amounts of estrogens and some glucocorticoids (da Silva et al., 2007; Kutovaja and Bhatia, 2014).

The anabolic androgenic steroid nandrolone decanote (ND) is a synthetic testosterone analogue produced essentially for medical uses. ND is in charge of the slim tissue synthesis (anabolism) and male characteristics development (androgyny) (Kang et al., 2014; Smith and Walker, 2014). As a result of the striking anabolic effect of the ND mainly in muscle tissue, this compound is excessively utilized by persons to ameliorate their bodily manifestation or athletic performance. In additions, ND promotes androgenization, activating masculinizing characteristics in both gender men and women (Hartgens and Kuipers, 2004; de Paiva Foletto et al., 2010). The therapeutic advantages of low dosages of ND stand in sharp contrast to the prospective health hazardous linked to the exaggerated doses self-administered not only by body builders and athletes but by a rising number of adolescent boys and girls (Clarka and Henderson, 2003; Cunha et al., 2005).

ND administration was reported to triggered hazardous effects on various organs; including the heart (Andrade et al., 2008), striated muscle (Fontana et al., 2012), brain (Tugyan et al., 2013), and liver (El Sherrif et al., 2013), however, studies of ND effects on the endocrine system generally and adrenal gland particularly were few in literature (Toscano et al., 1990; Pope et al., 2001). Therefore, the current study aimed to investigate the impacts of both the therapeutic and supraphysiological doses of ND on the adrenal cortex of the male rat from the histological and ultrastructural point of view.

The current study revealed that the adrenal cortices of rats treated with the therapeutic dose of ND illustrated mild alteration of the adrenocortical layers; ZG, ZF and ZR. On the other hand, the supraphysiological dose of ND induced severe destructive histological and ultrastructural alterations in the adrenal cortices of treated rats. One of these alterations was the obvious reduction in the thickness of ZG, ZF and ZR. This reduction occurred as a result of the compression in their component cells and due to shrinkage or degeneration of the organelles forming these cells, particularly the mitochondria, smooth endoplasmic reticulum and nuclei. Rebuffut et al., (1992) reported that the number of mitochondria and the cisternae of smooth endoplasmic reticulum were reduced significantly in the atrophied ZF of the rat adrenal cortex.
Variable degenerative changes in the cells of the three adrenocortical zones were recorded in the present study. Most cells lost their normal structure showing clear signs of necrosis represented as vacuolated cytoplasm and their nuclei revealed symptoms of pyknosis, karyorrhexis and karyolysis, in addition to the presence of fibrotic areas among the destructed cells of both ZG and ZF. These results are in accordance with those reported by Almeida et al., (2001), Illera et al., (2007), Silvan et al., (2007) and Ye et al., (2008) in their studies on the influence of dexamethasone, a potent synthetic glucocorticoid on rat adrenal gland. Similarly, Elshennawy and Aboelwafa (2011) recorded similar results post hydrocortisone treatment. The previous authors mentioned that dexamethasone or hydrocortisone decreased the adrenal gland weight due to the atrophy in the regions of the adrenal cortex, resulting in restraining the steroid secretion from the adrenocortical cells.

Also, accumulation of lipid droplets of various sizes was seen in the rat adrenocortical cells post-treatment with the supraphysiological dose of ND. Such alteration had also been previously reported by Almeida et al., (2001) in dexamethasone-treated rats particularly in the cells of ZF and ZR. In an attempt to explain this change, Hall, (1995) described that most of the utilized cholesterol in the biosynthesis of steroids is stocked in lipid droplets. Then the cholesterol ester in these lipid droplets is imparted to the inner membrane of the mitochondria and takes part of the pathway of steroid hormones biosynthesis as free cholesterol. While the accumulation of lipid droplets in adrenocortical cells may be deemed as a secondary phenomenon resulted from the inhibition of the sequence of reactions that convert the cholesterol to progesterone. Thence, it may be proposed that ND may inhibit the translocation of cholesterol resulting in the aggregation of lipid droplets in the cytoplasm of adrenocortical cells.

Post ND-treatment, the nuclei of the majority of adrenocortical cells of all regions manifested obvious signs of pyknosis, karyorrhexis and karyolysis. Parallel with the present observation, Almeida et al., (2006) and Elshennawy and Aboelwafa (2011) recorded almost similar results of devastating changes in the fine structural characteristics of the nuclei in their investigation of dexamethasone and hydrocortisone, respectively. Caraci et al., (2011) and Basile et al., (2013) displayed that supraphysiological doses of AASs caused apoptotic influences on a various cell types. 
Fig.1 Light micrographs of H\&E stained sections of adrenal gland of control rat

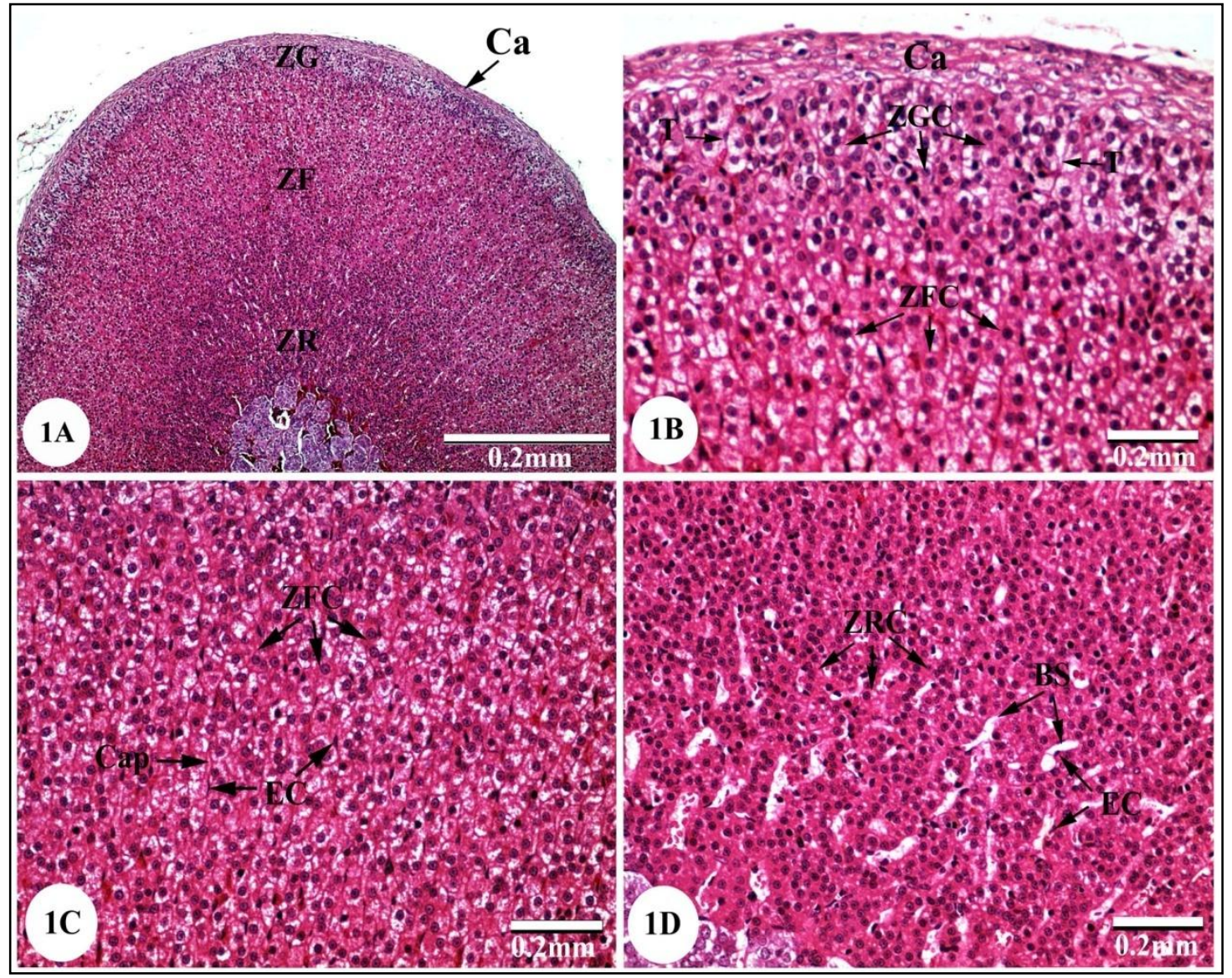

Fig.2 Light micrographs of H\&E stained sections of adrenal gland of ND therapeutic dose-treated rat

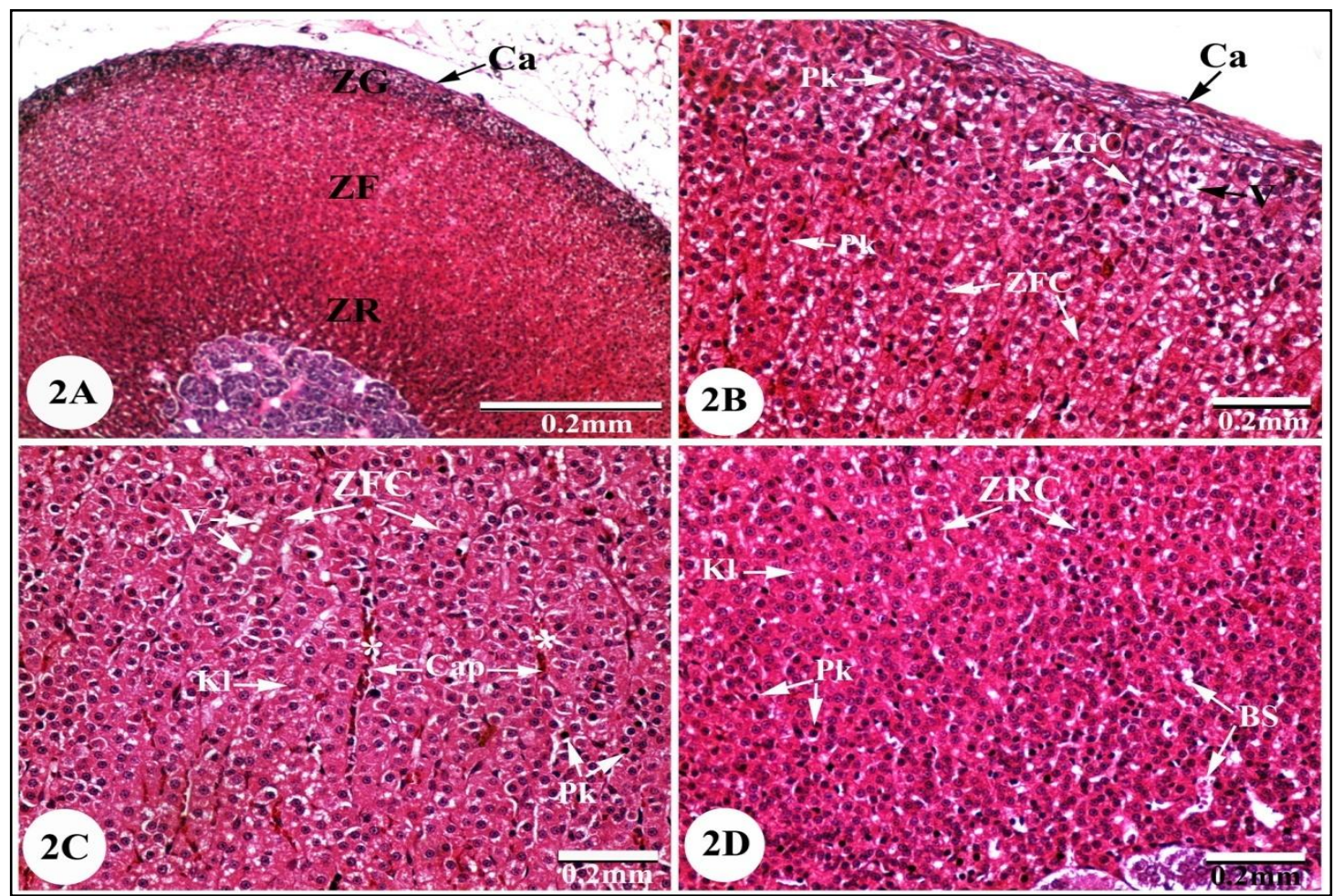


Fig.3 Light micrographs of H\&E stained sections of adrenal gland of ND supraphysiological dose-treated rat

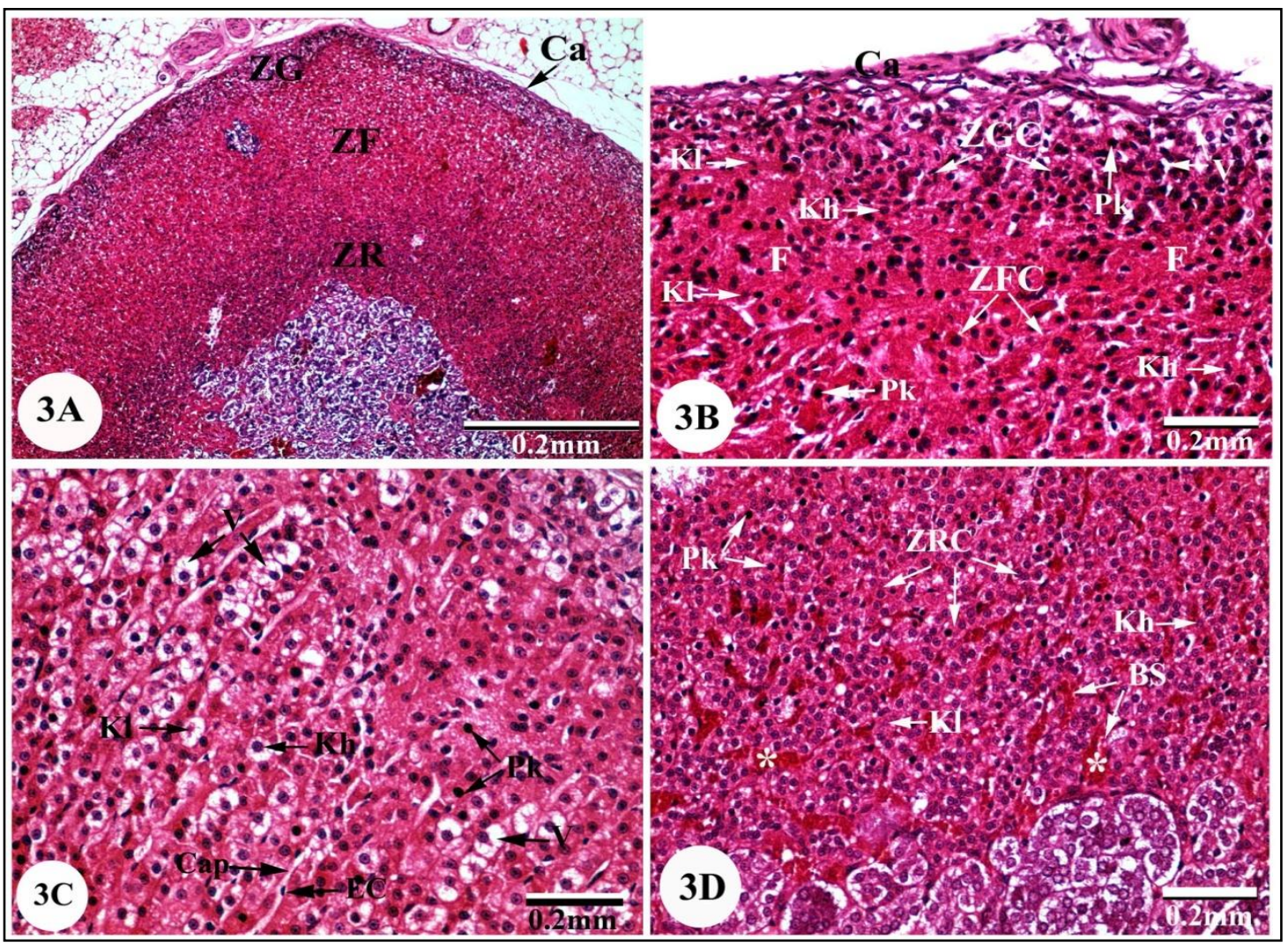

Fig.4 Electron micrographs of adrenal cortex of control rat
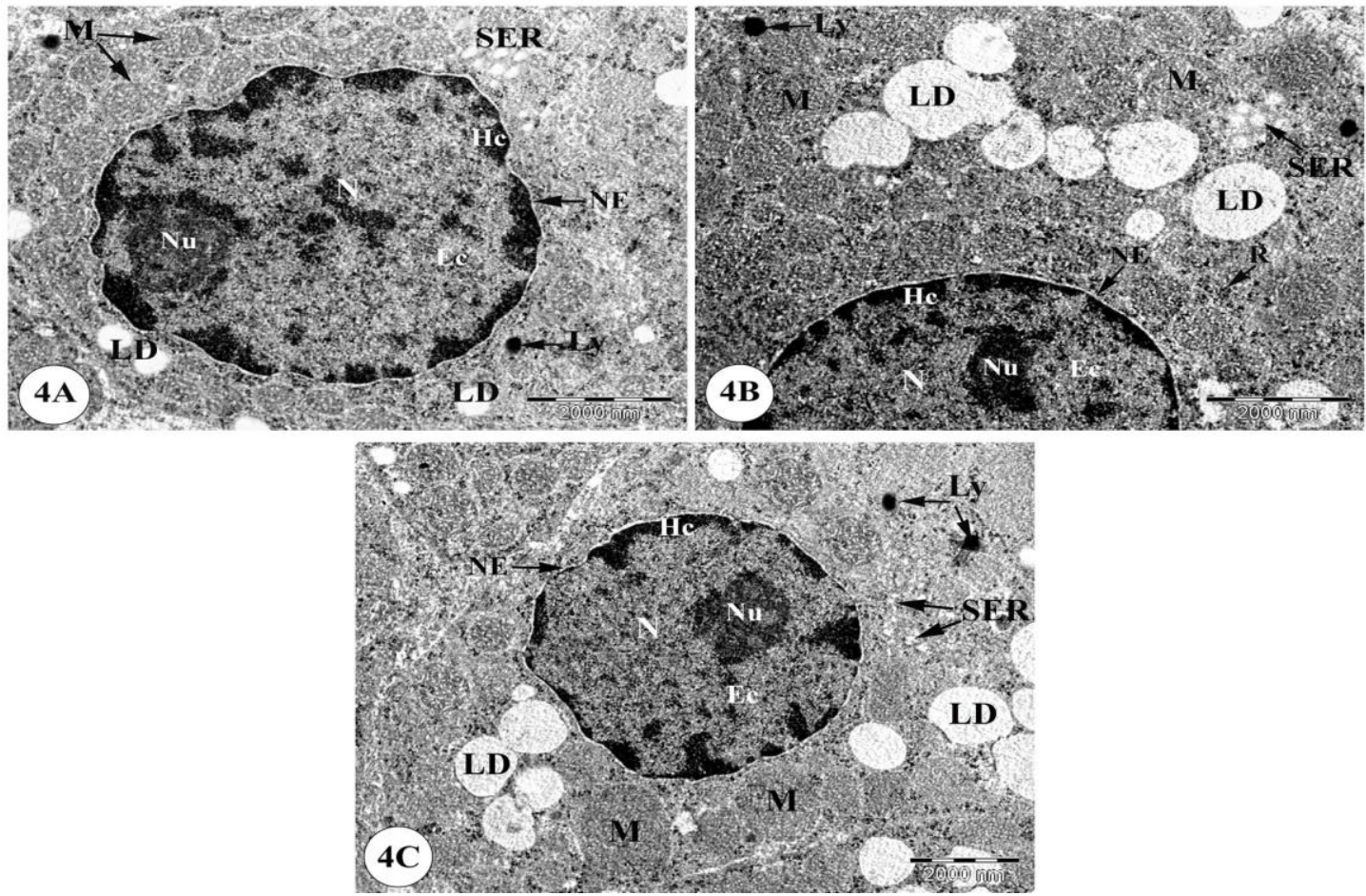
Fig.5 Electron micrographs of adrenal cortex of ND therapeutic dose-treated rats

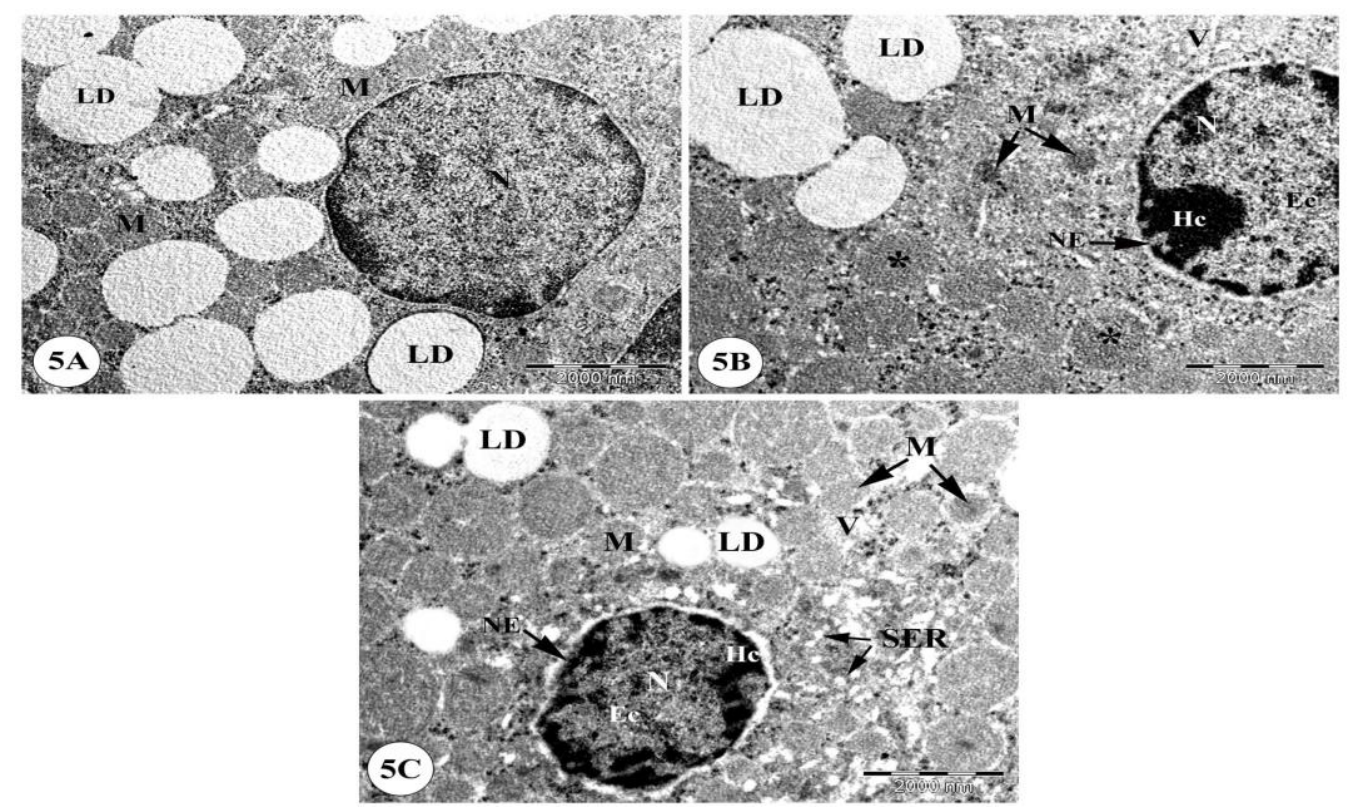

Fig.6 Electron micrographs of adrenal cortex of ND supraphysiological dose- treated rats

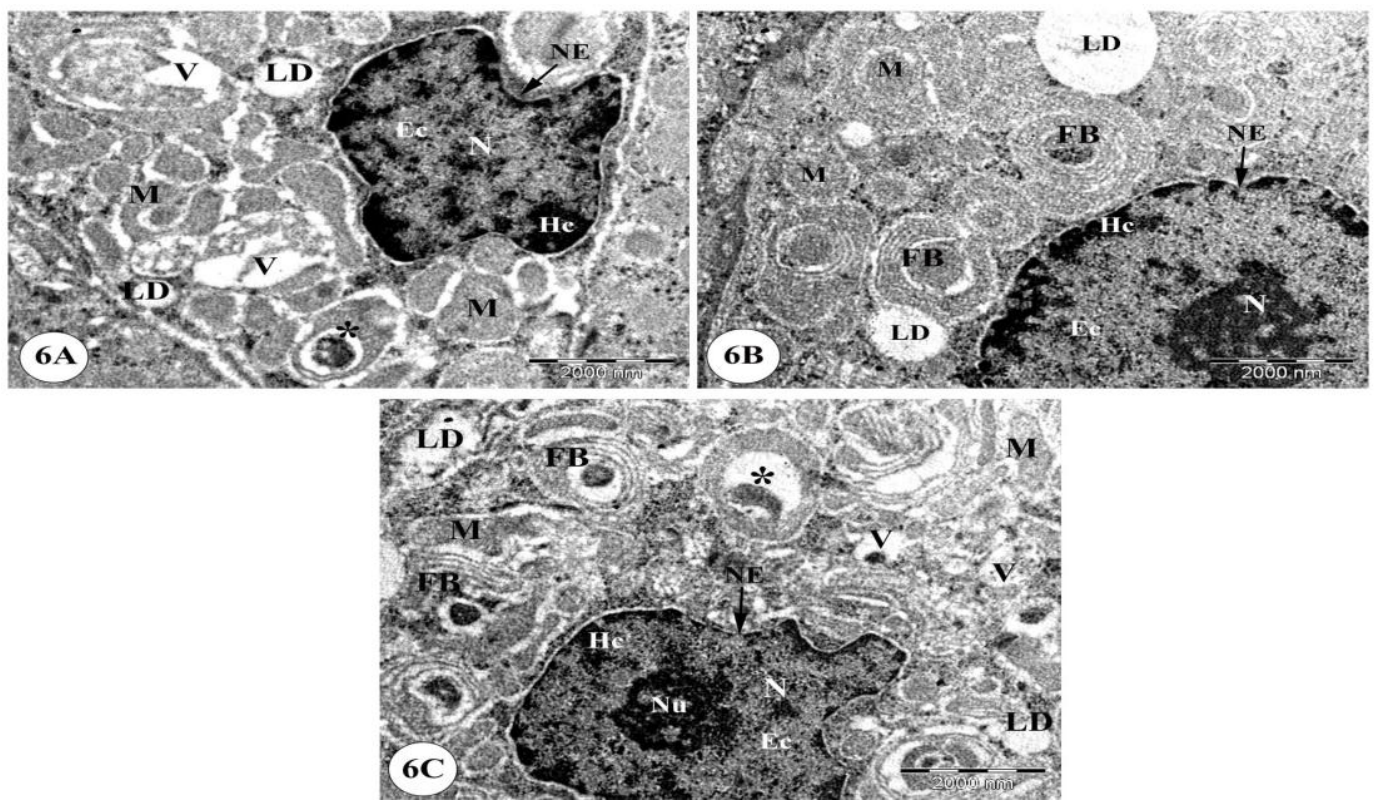

The appearance of fibrotic areas in the histological sections and fibrotic fingerprint-like configuration in the ultrastructural specimens here were affirmed previously by Guerrero et al., (2010) and Elshennawy and Aboelwafa (2011) in their valuable researches on the rat adrenal cortex post treatment with brown widow spider venom and hydrocortisone, respectively.
The hazardous alterations exhibited in the mitochondria and smooth endoplasmic reticulum following treatment with ND might be adequate to result in inhibition of the biosynthesis of steroid hormones. Coincides with the current results, Guerrero et al., (2010) mentioned that smooth endoplasmic reticulum and mitochondria have a considerable role in steroidogenesis in the adrenocortical cells through their participation in the coordinated functions of the enzyme 3 $\beta$-hydroxysteroid 
dehydrogenase (3ßHSD) and cytochrome P450, which are distributed between the smooth endoplasmic reticulum and mitochondria.

A considerable imbalance in the endocrine system was reported following AASs administration (Takahashi et al., 2004). The same authors mentioned that the androgen secreting ZR would most likely suffered damage post AAS abuse due to initiation of negative feedback mechanisms.

Most of the adverse impacts following the utilization of ND resulted from the enhancement of normal physiologic response to testosterone by either direct receptor agonist activity or suppression of steroid biosynthesis. As explained by Buttner and Thieme (2010), the toxic influences of AASs abuse might be related to the enhanced androgenic impacts, anabolic side effects, estrogenic side influences, and antiandrogenic effects from the suppression of the hypothalamus-pituitary-adrenal/gonadal axes (HPA/ HPG-axis).

The administration of ND decreased plasma concentrations of testosterone and androstenedione, as a result of the activation of the negative feedback loop of the HPA/HPG-axis and decrease concentrations of follicle-stimulating hormone (FSH) and luteinizing hormone (LH) (Daly et al., 2003; Garevik et al., 2011; Purkayastha and Mahanta, 2012). Such reduction in endogenous testosterone production caused diminished spermatogenesis, testicular atrophy, abnormal sperm morphology and reduced semen density leading to infertility (Torres-Calleja et al., 2001; Dohle et al., 2003; Takahashi et al., 2004).

In conclusion, the current histological and ultrastructural studies emphasis that the supraphysiologic dose of ND induced serious hazardous alterations in the adrenal cortex which might be reflected in suppression of steroid hormones biosynthesis. Therefore, these results are exceedingly pertinent to highlight the prospective hazard of the indistinctive utilization of the AASs in sports by athletes and bodybuilders, as well as by adolescents.

\section{References}

Allouh, M.Z. and Rosser, B.W. 2010. Nandrolone decanoate increases satellite cell numbers in the chicken pectoralis muscle. Histol. Histopathol., 25(2): 133-140.

Almeida, H., Matos, L., Ferreira, J. and Neves, D. 2006. Age-related effects of dexamethasone administration in adrenal zona reticularis. Ann. NY. Acad. Sci., 1067(1): 354-360.

Almeida, H., Ros-Dominguez, S., Ribeiro, N., Magalhaes, M.C. and Magalhaes, M.M. 2001. Dexamethasone administration during ageing- a structural and biochemical study on rat adrenal cortex. Biol. Cell, 93: 372-387.

Andrade, T.U., Santos, M.C., Busato, V.C., Medeiros, A.R., Abreu, G.R., Moyses, M.R. and Bissoli, N.S. 2008. Higher physiological doses of nandrolone decanoate do not influence the Bezold-Jarish reflex control of bradycardia. Arch. Med. Res., 39: 27-32.

Bancroft, J.D. and Gamble, M. 2002. Theory and practice of histological techniques, $5^{\text {th }}$. ed. London, New York, Philadelphia: Churchill, Livingstone.

Basile, J.R., Binmadi, N.O., Zhou, H., Yang, Y.H., Paoli, A. and Proia, P. 2013. Supraphysiological doses of performance enhancing anabolic-androgenic steroids exert direct toxic effects on neuron-like cells. Front. Cell Neurosci., 7: 69.

Buttner, A. and Thieme, D. 2010. Side effects of anabolic androgenic steroids: pathological findings and structure-activity relationships. Handb. Exp. Pharmacol., 195: 459-484.

Caraci, F., Pistara, V., Corsaro, A., Tomasello, F., Giuffrida, M. L., Sortino, M. A., Nicoletti, F. and Copani, A. 2011. Neurotoxic properties of the anabolic androgenic steroids nandrolone and methandrostenolone in primary neuronal cultures. $J$. Neurosci. Res., 89: 592-600.

Chawla, B., Iqbal, F. M. and Chawla, M. S. 2009. Nandrolone decanoate for the treatment of erythropoietin refractory anemia: a case series. Comprehensive Therapy, 35(3-4): 199-203.

Clark, A. S. and Henderson, L. P. 2003. Behavioral and physiological responses to anabolic-androgenic steroids. Neurosci. Biobehav. Rev., 27: 413-436.

Cunha, T. S., Tanno, A. P., Costa Sampaio Moura, M. J. and Marcondes, F. K. 2005. Influence of high-intensity exercise training and anabolic androgenic steroid treatment on rat tissue glycogen content. Life Sci., 77: 1030-1043.

Daly, R. C., Su, T.P., Schmidt, P. J., Pagliaro, M., Pickar, D. and Rubinow, D. R. 2003. Neuroendocrine and behavioral effects of high-dose anabolic steroid administration in male normal volunteers. Psychoneuroendocrinology, 28: 317-331.

da Silva, B. B., Lopes-Costa, P. V., Rosal, M. A., Pires, C. G., dos Santos, L. G., Gontijo, J. A., Alencar, A. P. and de Jesus Simões, M. 2007. Morphological and morphometric analysis of the adrenal cortex of androgenized female rats. Gynecol. Obstet. Invest., 64: 44-48. 
de Paiva Foletto, M., Mareze-Costa, C., Ferrari, F., Franzóide-Moraes, S. and Mara Segatelli, T. 2010. Effect of the nandrolone decanoate on the efficiency of spermatogenesis of sedentary rats and rats subjected to physical training. Acta Scientiarum Health Sci., 32(1):17-22.

Dohle, G. R., Smit, M. and Weber, R. F. 2003. Androgens and male fertility. World J. Urol. 21: 341-345.

Dykstra, M. J., Mann, P. C., Eiwell, M. R. and Ching, S. V., 2002. Suggested standard operating procedures (SOPs) for the preparation of electron microscopy samples for toxicology/pathology studies in a GLP environment. Toxicol. Pathol., 30(6): 735-743.

El Sherrif, Y., Potts, J. R., Howard, M. R., Barnardo, A., Cairns, S., Knisely, A. S. and Verma, S. 2013. Hepatotoxicity from anabolic androgenic steroids marketed as dietary supplements: contribution from ATP8B1/ABCB11 mutations? Liver Int., 33: 12661270.

Elshennawy, W. W. and Aboelwafa, H. R. 2011. Hydrocortisone impact on the structural and ultrastructural characteristics of mammalian adrenal cortex. J. Am. Sci., 7(5):1053-1064.

Fawcett, D. W. and Jensh, R. P. 2002. Endocrine Glands. In: Bloom \& Fawcett's Concise Histology. 2nd ed., London, New York, New Delhi. PP. 261-264.

Fontana, K., Rocha, T. and da Cruz-Hofling, M. A. 2012. Regulation of neuronal and endothelial nitric oxide synthase by anabolic-androgenic steroid in skeletal muscles. Histol. Histopathol., 27: 1449-1458.

Fudala, P. J., Weinrieb, R. M., Calarco, J. S., Kampman, K. M. and Boavdman, C. 2003. An evaluation of anabolic-androgenic steroid abusers over a period of 1 year: seven case studies. Ann. Clin. Psychiatry, 15(2): 121-130.

Garevik, N., Strahm, E., Garle, M., Lundmark, J., Stahle, L., Ekstrom, L. and Rane A. 2011. Long term perturbation of endocrine parameters and cholesterol metabolism after discontinued abuse of anabolic androgenic steroids. J. Steroid Biochem. Mol. Biol., 127: 295-300.

Guerrero, B., Finol, H. J., Reyes-Lugo, M., Salazar, A. M., Sanchez, E. E., Estrella, A., Roschman-Gonzalez, A., Ibarra, C., Salvi, I. and Rodriguez-Acosta, A. 2010. Activities against hemostatic proteins and adrenal gland ultrastructural changes caused by the brown widow spider Latrodectus geometricus (Araneae: Theridiidae) venom. Comp. Biochem. Physiol., 151(C): 113-121.

Gruber, A. J. and Pope, H. G. 2000. Psychiatric and medical effects of anabolic-androgenic steroid use in women. Psychother. Psychosom., 69: 19-26.

Hall, P. F. 1995. The roles of microfilaments and intermediate filaments in the regulation of steroid synthesis. J. Steroid Biochem. Mol. Biol., 55(5-6): 601-605.

Hallberg, M. 2011. Impact of anabolic androgenic steroids on neuropeptide systems. Mini Rev. Med. Chem., 11: 399-408.

Hartgens, F., Kuipers, H., 2004. Effects of androgenicanabolic steroids in athletes. Sports Medicine 34, 513554.

Illera, J. C., Pena, L., Martinez-Mateos, M. M., Camacho, L., Blass, A., Garcia-Partida, P., Illera, M. J. and Silvan, G. 2007. The effect of long-term exposure to combinations of growth promoters in Long Evans rats. Part 2: adrenal morphology (histopathology and immunochemical studies). Analytic. Chim. Acta, 586(112): 252-258.

Kamel, H. K., Perry, H. M. and Morley, J. E. 2001. Hormone replacement therapy and fractures in older adults. J. Am. Geriatr., 49(2): 179-187.

Kanayama, G., Hudson, J. I. and Pope, Jr. H. G. 2010. Illicit anabolic-androgenic steroid use. Horm. Behav., 58: 111-121.

Kang, H. J., Moon, M. J., Lee, H. Y. and Han, S. W. 2014. Testosterone alters testis function through regulation of piRNA expression in rats. Mol. Biol. Rep., 41(10): 6729-6735.

Kicman, A. T. 2008. Pharmacology of anabolic steroids. $B r$. J. Pharmacol., 154: 502- 521.

Kindlundh, A. M. S., Agekull, B., Isacson, D. G. L. and Nyberg, F. 2001. Adolescent use of anabolicandrogenic steroids and relations to self-reports of social, personality and health aspects. Eur. J. Public Health, 11: 322-328.

Kuhn, C. M. 2002. Anabolic steroids. Recent Prog. Horm. Res., 57: 411-434.

Kurling, S., Kankaanpaää, A., Ellermaa, S., Karila, T. and Seppälä, T. 2005. The effect of sub-chronic nandrolone decanoate treatment on dopaminergic and serotonergic neuronal systems in the brains of rats. Brain Res., 1044: 67-75.

Kutovaja, J. and Bhatia, K. 2014. Clinical aspects of endocrinology: parathyroid and adrenal gland disorders. Anaesthesia Intensive Care Med., 15(10): 441-445.

Lee, D. M., Min, T., Choi, I., Cheon, Y., Chun, T., Park, C. S. and Lee, K. 2010. Feeding effect of an anabolic steroid, Nandrolone on male rat testis. Asian-Aust. J. Anim. Sci., 23(12):1566-1577.

Lindblom, J., Kindlundh, A. M. S., Nyberg, F., Bergstrom, L. and Wikberg, J. E. S. 2003. Anabolic androgenic steroid nandrolone decanote reduces hypothalamic proopiomelanocortin mRNA levels. Brain Res., 986: 139-147.

Magnusson, K., Hanell, A., Bazov, I., Clausen, F., Zhou, Q. and Nyberg, F. 2009. Nandrolone decanoate 
administration elevates hippocampal prodynorphin mRNA expression and impairs Morris water maze performance in male rats. Neurosci. Lett., 467: 189193.

Matrisciano, F., Modafferi, A. M. E., Togna, G. I., Barone, Y., Pinna, G., Nicoletti, F. and Scaccianoce, S. 2010. Repeated anabolic androgenic steroid treatment causes antidepressant-reversible alterations of the hypothalamic-pituitary-adrenal axis, BDNF levels and behavior. Neuropharmacology, 58: 1078-1084

Mottram, D. R. and George, A. J. 2000. Anabolic steroids. Baillieres Bed Pract. Clin. Endocrinol. Metab., 14: 5569.

Perry, P. J., Kutscher, E. C., Lund, B. C., Yates, W. R., Holman, T. L. and Demers, L. 2003. Measures of aggression and mood changes in male weightlifters with and without androgenic anabolic steroid use. $J$. Forensic Sci., 48: 646-651.

Pope, J. A., Benghuzzi, H., England, B. and Cason, Z. 2001. Morphometric analysis of the adrenal compartments exposed to sustained delivery of androgens. Biomed Sci Instrum., 37: 155-60.

Purkayastha, S. and Mahanta, R. 2012. Effect of nandrolone decanoate on serum FSH, LH and testosterone concentration in male albino mice. World J. Life Sci. Med. Res., 2(3): 123-127.

Rainer, Q., Speziali, S., Rubino, T., Dominguez-Lopez, S., Bambico, F. R., Gobbi, G. and Parolaro, D. 2014. Chronic nandrolone decanoate exposure during adolescence affects emotional behavior and monoaminergic neurotransmission in adulthood. Neuropharmacology, 83: 79-88.

Rebuffat, P., Belloni, A. S., Rocco, S., Andreis, P. G., Neri, G., Maalendowicz, L. K., Gottardo, G., Mazzocchi, G. and Nussdorfer, G.G. 1992. The effects of ageing on the morphology and function of the zonae fasciculata and reticularis of the rat adrenal cortex. Cell Tissue Res., 270: 265-272.

Saha, B., Rajadhyaksha, G. C. and Ray, S. K. 2009. Beneficial effects of nandrolone decanoate in wasting associated with HIV. J. Ind. Med. Assoc., 107(5): 295299.

Sicard, F., Ehrhart-Bornstein, M., Corbeil, D., Sperber, S., Krug, A. W., Ziegler, C. G., Rettori, V., McCann, S. M. and Bornstein S. R. 2007. Age-dependent regulation of chromaffin cell proliferation by growth factors, dehydroepiandrosterone (DHEA), and DHEA sulfate. Proc. Natl. Acad. Sci. USA., 104: 2007-2012.

\section{How to cite this article:}

Hanaa R. Aboelwafa. 2017. Impact of the Anabolic Androgenic Steroid "Nandrolone Decanote" on the Histological and Ultrastructural Characteristics of Adrenal Cortex of Adult Male Rats. Int.J.Curr.Res.Aca.Rev. 5(6), 69-80.

doi: https://doi.org/10.20546/ijcrar.2017.506.010
Silvan, G., Martinez-Mateos, M. M., Blass, A., Camacho, L., Gonzalez-Gil, A., Garcia-Partida, P. and Illera, J. C. 2007. The effect of long-term exposure to combinations of growth promoters in Long Evans rats. Part 1: Endocrine adrenal function. Anal. Chim. Acta, 586(1-20): 246-251.

Silvia Racca, S., Piccione, F., Spaccamiglio, A., Carriero, V. M. A., Francia, S. D., Cangemi, L., Esculapio, P., Papotti, M., Migliaretti, G., Portaleone, P., Carlo, F. D. and Abbadessa, G. 2012. Effects of sub-chronic nandrolone administration on hormonal adaptive response to acute stress in rats. Psychoneuroendocrinology, 37: 1234-1247.

Smith, L. B. and Walker, W. H. 2014. The regulation of spermatogenesis by androgens. Semin. Cell Dev. Biol., 30: 2-13.

Takahashi, M., Tatsugi, Y. and Kohno, T. 2004. Endocrinological and pathological effects of anabolicandrogenic steroid in male rats. Endocr. J., 51: 425434.

Talih, F., Fattal, O., Malone Jr. D. 2007. Anabolic steroid abuse: psychiatric and physical costs. Cleveland Clinic J. Med., 74: 341-344.

Tamaki, T., Shiraishi, T., Takeda, H., Matsumiya, T., Roy, R. R. and Edgerton, U. R. 2003. Nandrolone decanote enhances hypothalamic biogenic amines in rats. Med. Sci. Sports Exerc., 35(1): 32-38.

Torres-Calleja, J., Gonzalez-Unzaga, M., DeCelis-Carrillo, R., Calzada-Sanchez, L. and Pedron, N. 2001. Effect of androgenic anabolic steroids on sperm quality and serum hormone levels in adult male bodybuilders. Life Sci., 68: 1769-1774

Toscano, V., Caiola, S., Maroder, M., Adamo, M. V., Argiolas, L., Familiari, A. and Familiari, G. 1990. Effects of dihydrotestosterone treatment on adrenal gland function and morphology in adult female guinea-pigs. J. Steroid Biochem., 36: 89-97.

Tugyan, K., Ozbal, S., Cilaker, S., Kiray, M., Pekcetin, C., Ergur, B. U. and Kumral, A. 2013. Neuroprotective effect of erythropoietin on nandrolone decanoateinduced brain injury in rats. Neurosci Lett., 533: 28-33.

Ye, P., Kenyon, C. J., Mackenzie, S. M., Nichol, K., Seckl, J. R., Fraser, R., Connell, J. M. and Davies, E. 2008. Effects of ACTH, dexamethasone and adrenalectomy on $11 \beta$-hydroxylase (CYP11B1) and aldosterone synthase (CYP11B2) gene expression in the rat central nervous system. J. Endocrinol., 196: 305-311. 